\title{
EVANGelHo ETERNO. HeRmenêUTICA E FIM DA HISTÓRIA EM JOAQUIM DE FIORE ${ }^{1}$
}

\author{
Noeli Dutra Rossatto ${ }^{2}$
}

Resumo: O estudo trata o tema do Evangelho eterno, em Joaquim de Fiore (1132-1202). A principal hipótese é que Joaquim entende o Evangelho eterno como uma nova mensagem derivada da compreensâo espiritual das Escrituras, válida para o terceiro estado do mundo, o chamado estado espiritual. A defesa dessa hipótese implica a rejeiçăo da ideia de que há uma nova escritura para o terceiro estado do mundo, como quer o espiritual franciscano Geraldo de Borgo, condenado em 1255. Em outro momento, significa admitir, diferentemente da maioria dos estudiosos do tema, que haveria um novo evangelho, o Evangelho eterno, em substituição ao Evangelho de Cristo e de seu Reino, destinado a vigorar soberanamente, no terceiro estado espiritual.

Palavras-chave: Joaquim de Fiore. Franciscanos. Evangelho eterno. Hermenêutica. Fim da história.

\section{INTRODUÇÁo}

A polêmica expressão Evangelium eternum, tomada do último livro bíblico, o Apocalipse atribuído a João, foi acunhada pela obra do abade Joaquim de Fiore, escrita ao final do século XII. No entanto, a sua popularização - e a posterior condenação -, ao que tudo indica, se deve mais ao Liber introductorius in Evangelium eternum (Livro da introdução ao Evangelho eterno), do jovem franciscano Geraldo de Borgo San Donnino, publicado em 1254, um ano depois condenado como herético e até hoje desaparecido. De qualquer modo, a análise medieval mais minuciosa do tema do Evangelho eterno foi aquela realizada pela Comissão de Anagni, reunida entre 1254-55, a pedido do papa Alexandre IV, do que resultou a indicaçáo de sua condenação por heresia, junto com a obra de Geraldo de Borgo.

\footnotetext{
${ }^{1}$ http://dx.doi.org/10.1590/S0101-31732018000100004

2 Professor do Programa de Pós-Graduação em Filosofia (PPG-Fil) e do Programa de Pós-Graduação em História (PPGH) da Universidade Federal de Santa Maria (UFSM), Santa Maria, RS - Brasil. E-mail: <rossatto.dutra@gmail.com>.

Doutor em História da Filosofia (Medieval) pela Universidade de Barcelona, Espanha. É autor de vários livros, entre os quais, Joaquim de Fiore. Trindade e Nova Era (Porto Alegre, RS: EDIPUCRS, 2004).
}

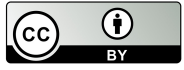

This is an open-access article distributed under the terms of the Creative Commons Attribution License. 
A pergunta que propomos inicialmente, desde a perspectiva da revisão de literatura, é a seguinte: até que ponto o chamado Evangelho eterno, propagado de diferentes modos, ao longo do pensamento ocidental, tem amparo teórico na obra de Joaquim de Fiore?

Importante também é uma questão atual que teremos em vista: em que, de fato, a proposta joaquimita implica a superação do Evangelho de Cristo e, em suma, da própria noção de cristianismo?

Dessa perspectiva, levamos adiante a hipótese de que a proposta joaquimita pode ser mais contundente que aquela contida em discussóes contemporâneas - e aqui pensamos em Paul Ricoeur (1976), O conflito das interpretaçôes (especialmente o Prefácio a Bultmann), e, sobretudo, em Gianni Vattimo (2004), Depois da cristandade (Primeira Parte - 2. Os ensinamentos de Gioacchino) -, que tentam retomar, em chave da hermenêutica contemporânea, a crítica da religião, da Igreja e, em especial, do cristianismo. A nosso ver, nesses autores, assim como no atual estado da questão na historiografia joaquimita, a reconstrução do sentido que passa pela efetiva superação histórica da igreja, da cristandade e, na perspectiva joaquimita, do próprio cristianismo, como uma etapa intermediária entre o estado paterno e o espiritual, continua ainda uma via desestimada e condenada.

A expressão Evangelho eterno, com certeza, foi tomada por Joaquim do Apocalipse e indica uma nova mensagem a ser propagada. Está citada uma única vez por seu autor, no contexto do anúncio do Juízo Final, em que ele apresenta a seguinte visão: "Vi então outro anjo, que voava no ápice do céu, com uma mensagem a anunciar aos habitantes da terra, a toda naçáo, tribo, língua e povo - um Evangelho eterno" (Ap 14,6).

A outra questão que propomos tem como alvo o próprio pensamento joaquimita: o Evangelho eterno brota da hermenêutica espiritual dos dois testamentos bíblicos ou, de outro modo, acarreta o surgimento de uma nova escritura? Será, de fato, um novo testamento espiritual destinado a reinar soberanamente, no terceiro estado do mundo?

É certo que Joaquim de Fiore retoma a citada passagem apocalíptica em vários momentos de sua obra. É igualmente certo que esses momentos estáo discriminados nas atas do Protocolo de 1255 - também conhecido como Protocolo de Anagni (VERARDI, 1992; ROSSATTO et al., 2010) - que resultam da reunião da Comissão de Anagni, em que foram avaliados o texto de Geraldo de Borgo e as principais obras de Joaquim de Fiore. 
Não é menos certo que a marca indelével do Evangelho eterno, como indica Henri Lefebvre (1976, p. 40), se perpetuou, de forma "subterrânea, profunda e oculta”, na posterior difusão da obra joaquimita. Por isso, é possível sugerir, de saída, que o grande legado de Geraldo de Borgo talvez tenha sido ter posto em evidência essa vertente hermenêutica - um "mito», nas palavras de Reeves e Gould (2000) - associada ao Evangelho eterno. Doravante, muitos autores que, de um ou de outro modo, se envolveram com a obra de Joaquim, irão identificá-la com o próprio Evangelho eterno. Tal é o caso da chamada redescoberta do Evangelho eterno pelos filósofos alemães do século XIX, notadamente Lessing, Schiller e Schelling (DE LUBAC, 1979); ou a conhecida tradução francesa de fragmentos dos principais textos do abade, por Emmanuel Aegerter (1928), intitulada L'Evangile éternel, de início do século XX. O mesmo pode ser dito de Mircea Eliade (1996, p. 132), que, em $O$ mito do eterno retorno, identifica a produção joaquimita com o Evangelho eterno, $\mathrm{e}$ de tantos outros estudos mais recentes.

Em um primeiro momento, avaliaremos a problemática do Evangelho eterno, na historiografia joaquimita mais recente. Depois, retomaremos o enfoque da historiografia medieval, sobretudo o Protocolo de 1255, o qual é o principal documento que registra a polêmica em torno do Evangelho eterno, nos círculos do franciscanismo espiritual. Por fim, analisaremos três momentos distintos, em que o tema aparece nos textos de Joaquim de Fiore.

\section{O EVANGELHO ETERNO NA HISTORIOGRAFIA JOAQUIMITA ATUAL}

Marjorie Reeves e Warwick Gould (2000) publicaram um importante livro, intitulado Joachim of Fiore and the myth of the Eternal Evangel in the nineteenth century, em que, entre outras coisas, defendem que Joaquim não previa nenhum testamento para o terceiro e último estado do mundo e que, tampouco, o Evangelho eterno se identificaria com a mais alta compreensão espiritual da Escritura. Por fim, eles concluem que, apesar de Joaquim utilizar expressóes tais como Nova Igreja ou Novo Evangelho, elas não estão referidas em momento algum ao terceiro estado do mundo (REEVES; GOULD, 2000, p. 8).

Henry Mottu (1983, p. 129), em um texto denominado La manifestation de l'Esprit selon Joachim de Flora, faz suas as palavras de Antonio Crocco (1954), sublinhando que os espirituais franciscanos e, em particular, Geraldo de Borgo, não compreenderam o sentido essencialmente pneumático do Evangelho eterno, indicado por Joaquim; e que, além do mais, a expressão não 
sugere de modo algum uma nova escritura, a Sacra Escritura do terceiro estado do mundo, mas seria a mais sublime e espiritual compreensão (spiritualis intellectus ou spiritualis intelligentia) do Evangelho de Cristo - ou, antes, dos dois testamentos.

Essas diferentes avaliaçóes do tema concordam a respeito de um ponto crucial: o Evangelho eterno não indica uma nova escritura ou um novo testamento para o terceiro estado do mundo. Náo vemos grandes dificuldades em aceitar tal premissa, desde que se leve em conta que estamos nos referindo a um terceiro testamento escrito. Resta, contudo, decidir a propósito de um terceiro testamento sem letra: um evangelho não escrito.

Ao lado disso, os autores citados discordam a respeito de um aspecto não menos importante, ao entenderem de forma diversa a relação entre o Evangelho eterno e a mais alta compreensão espiritual (intellectio spiritualis), a qual resultaria da leitura por concórdia (per concordiam) dos dois testamentos bíblicos. Para Reeves e Gould (2000, p. 10), o Evangelho eterno não pode ser identificado com a mais alta compreensão espiritual dos dois testamentos; para Crocco (1954) e Mottu (1984, p. 130), de outro modo, esse evangelho seria o próprio sentido espiritual das Escrituras, decorrente da hermenêutica por concórdia dos dois testamentos bíblicos.

\section{O que, entáo, indica a expressão Evangelho eterno?}

Reeves e Gould (2000, p. 11), na continuação, concedem que as interpretaçóes mais fiéis ao joaquimismo são aquelas que associam o Terceiro testamento ao Evangelho de João ou que utilizam a imagem apocalíptica do Evangelho eterno para caracterizar o Terceiro testamento. Se, de fato, isso se comprovar, voltaremos entáo à questáo inicial: Joaquim propóe um Terceiro testamento espiritual? E mais, essa terceira escritura se identificaria propriamente com o Evangelho eterno? E ainda: o Evangelho eterno diz respeito ao Reino de Cristo ou ao reinado do Espírito?

A suposição de que o Evangelho eterno diz respeito tão somente à efetivação do Reino de Cristo é um ponto em que, de diferentes modos, a historiografia irá convergir. Por exemplo, Mottu, depois de assumir que o Evangelho eterno é sinônimo de Evangelho do Reino, acrescenta que é essa a mensagem específica da comunidade espiritual do terceiro estado, em sucessão ao Evangelho de Cristo, o qual, segundo ele, fora sequestrado pela Igreja dos clérigos, ao assumir os sacramentos, as instituiçóes e o modo de vida da transitória Igreja de Pedro. Ao que conclui: 
Il «Vangelo eterno" è il regno effetivo (regnum) del Vangelo di Cristo; è la sua futura realizzazione completa a riscontro della sua oddierna realizzazione parziale; è ciò che da esso procede e gli succede, almeno in quanto lettera. In breve, questo "Vangelo eterno", non scritto, "spirituale», escatologico è il compimento del Vangelo scritto, carnale, istituzionale, di cui è, a rigore, la assunzione. (MOTTU, 1983, p. 130).

Tal avaliação é a mesma que se encontra no Primeiro Tomo do bastante conhecido La postérité spirituelle de Joachim de Flora - de Joachim a Schelling, do cardeal francês Henri de Lubac, publicado em 1979. Ao retomar a perspectiva da historiografia mais antiga, ele irá identificar o Evangelho eterno com o que chama de "Evangelho espiritual de Cristo». Assim, ele escreve:

La méditation de Joachim sur la Écriture ne lui fait pas entrevoir un nouvel évangile historique; ce qu'elle lui découvre, c'est l'approche au sein même de l'histoire d'une "prodigieuse palingénésie», d'où doit émerger véritablement "une outre Église», porteuse de "L'Évangile spirituel du Christ», ou plus exactement peut-être "Évangile en esprit», "procédant de l'Évangile du Christ». Alors l'Esprit-Saint, "nous enseignant toute vérité, nous fera désirer le jour définitif de l'entrée dans la gloire» (Psalt. f. 260). C'est là ce que saint Jean, dans son Apocalypse, dénommait «l'Évangile éternel». (DE LUBAC, 1979, p. 49-50).

Podemos, sem reservas, concordar com os dois autores, no que se refere à compreensão de que o Evangelho eterno não implicaria uma Terceira escritura: um Terceiro testamento para o terceiro estado do mundo, "a sacra Escritura do terceiro estado"; ou, em última análise, "um novo evangelho histórico". Não obstante, deve ficar claro desde já que isso só é válido na medida em que nos referimos a uma terceira letra escrita, pois, a nosso ver, o Evangelho eterno, em coerência com a proposta joaquimita, pretende ser uma escritura sem letra (sine littera) que passa a vigorar no terceiro estado espiritual. A propósito, podemos dizer que, no geral, esses autores vão concordar nesse ponto.

Mais importante, porém, não é o ponto em que historiografia converge, senão a discrepância a respeito de um aspecto fundamental: a identificação entre o Evangelho eterno e a compreensão espiritual (intellectio spiritualis) das Escrituras, resultante da aplicação da hermenêutica por concórdia.

Para Reeves e Gould, a mais alta compreensão espiritual não pode ser identificada com o Evangelho eterno, o que nos levaria a inferir que o significado desse evangelho não poderia ser derivado da compreensão espiritual 
dos dois testamentos, obtida pela hermenêutica por concórdia, tal como quer Mottu. Quanto a isso, poderíamos desde já afiançar que é possível entender que a mais alta compreensão espiritual das Escrituras é o próprio Evangelho eterno, tendo em vista as razóes que daremos mais adiante.

Dois aspectos fundamentais ainda nos separam da historiografia. Por razôes que pretendemos deixar mais claras, na sequência, não entendemos que o Evangelho eterno pode ser identificado plenamente com o "Evangelho espiritual de Cristo", como quer De Lubac. Tampouco que indique tão somente "o cumprimento do Evangelho de Cristo" ou mesmo que seja apenas "o Reino efetivo do Evangelho de Cristo”, como assinala Mottu. É certo que, em sentido histórico, para Joaquim, as principais figuras bíblicas, que compóem os dois testamentos, se repetem ao longo dos três estados da história. E é certo também que, ao ingressar no terceiro estado espiritual, alcançaríamos tudo aquilo que, no segundo, ainda estava revelado de forma parcial, figurada e enigmática. Mas isso não é tudo: não se pode esquecer, em momento algum, que haverá algo novo a acompanhar a repetição dos personagens, ao longo dos três estados; e que terá de ocorrer a plena realização das principais figuras bíblico-históricas, no terceiro estado do mundo. E tudo isso articula o passado e o futuro, tomando por base a dialética entre o que é próprio a cada uma das três pessoas da Trindade e o que é comum a todas elas.

Segundo a teoria trinitária de Joaquim, a relação entre o que é comum e o que é próprio às três pessoas da tríade divina se mostra menos visível, nos pontos de entrelaçamento dos três estados do mundo, tendo em vista que, nesses momentos, temos a intensa atuação de mais de uma pessoa. Por isso, o que é próprio a cada uma delas se mostra de forma mais ou menos encoberta em algumas das divisóes da história por sete idades (aetates), três estados (status) e cinco tempos (tempora), ou mesmo no entrelaçamento das sequências de vinte e uma gerações (generationes). Não obstante, conforme assinala Joaquim de Fiore (1964c, f. 5d), no Liber introdutorius da Expositio in Apocalypsim, não pode restar dúvidas a respeito de que o terceiro estado será protagonizado em sua totalidade pelo Espírito; e que esse mesmo estado vem sempre indicado como um período "já não mais vivido sob o véu da letra, mas na plena liberdade espiritual” (iam non sub velamine litterae, sed in plena spiritus libertae), diferentemente do primeiro estado, vivido sob a lei (sub legem); e do segundo, sob o véu da letra do Evangelho (sub Evangelio) de Cristo. Ou ainda, conforme lemos na Concordia Novi ac Veteris Testamenti (JOAQUIM DE FIORE, 1964b, f. 112a): o terceiro estado será vivido "sob uma graça ampliada" (sub 
ampliori gratia), em contraste com o primeiro e o segundo, vividos, respectivamente, sob a lei (sub legem) e sob a graça (sub gratia).

De igual modo, na divisão da história por cinco tempos, a qual reproduz a imagem simétrica de cada uma das cinco relaçóes intratrinitárias, o quinto tempo, protagonizado apenas pelo Espírito (solo Spiritus), vem sempre assinalado como um período a ser vivido na plena compreensão espiritual (spiritualis intellectus).

Não levar isso em conta significa, entre outras coisas, eliminar do plano hermenêutico a novidade joaquimita - o seu "novo genere exponendi", o novo modo de expor as Escrituras que ele reivindica com entusiasmo, no Prefácio da Concordia - depositado mais propriamente em sua estratégia de interpretação por concórdia (JOAQUIM DE FIORE, 1964b, f. 2c). Desconsiderar isso conduz à descaracterização, no plano da manifestação histórica, de tudo aquilo que é próprio a cada uma das pessoas da Trindade e, em particular, à terceira pessoa. E, por fim, no plano eclesiológico, implica subordinar o terceiro estado espiritual ao segundo, entendendo que, no terceiro estado, apesar de a Igreja de Cristo não mais ser a protagonista, ainda assim continuaria no comando e estaria em plena vigência tudo aquilo que fora atribuído ao estado anterior, isto é, ao segundo estado de Cristo ou ao cristianismo. Foi precisamente esse pressuposto ambivalente que conduziu De Lubac à afirmação de que o Evangelho eterno é o "Evangelho espiritual de Cristo", e não o Evangelho do Espírito. Foi isso também que direcionou inadvertidamente a análise de Mottu, no sentido de ver apenas a realização de uma "comunidade cristã perfeita", e não de uma comunidade espiritual; ou, no melhor dos casos, a ver tão somente uma interpretação solus Spiritus que, apesar de ser diferente da hermenêutica do solus Scriptura reformista, continuaria alimentando um cristianismo espiritual do terceiro estado do mundo (MOTTU, 1983, p. 87ss).

Tais ilaçôes, em última instância, carregam consigo os mesmos problemas encontrados na grande maioria das teorias trinitárias da tradição (ROSSATTO, 2004). Essas teorias, ao não darem o devido crédito e lugar ao terceiro termo da tríade, o Espírito Santo, acabam por não encontrar na história um período correspondente a ele. Da perspectiva joaquimita, de dois modos essas interpretaçôes excluem a presença do Espírito, na história: a primeira vez, ao admiti-lo apenas como procedente do Pai e do Filho; a segunda, ao negá-lo como protagonista do terceiro estado da história. 
De tudo que foi destacado, três aspectos ainda terão ser examinados à luz da historiografia medieval e dos textos joaquimitas, a saber:

1) se o Evangelho eterno, de fato, corresponde a uma nova escritura, no sentido de uma nova letra escrita ou de um Terceiro testamento histórico, para vigorar no terceiro estado;

2) se e em que medida o Evangelho eterno poderá ser identificado com a compreensão espiritual (spiritualis intellectus), alcançada pela hermenêutica por concórdia dos dois testamentos;

3) e, por último, se o Evangelho eterno é apenas o cumprimento do Reino de Cristo, com o significado restrito ao Evangelho do Reino de Cristo ou Evangelho Espiritual de Cristo.

\section{O Evangelho eterno em Geraldo de Borgo}

Parece plausível entender, de acordo com as atas do Protocolo de 1255, que Geraldo de Borgo, em coerência com o simbolismo joaquimita referente à teoria dos três estados do mundo, passou a associar de modo consequente o Antigo Testamento ao primeiro céu, o Novo Testamento ao segundo, e o Evangelho eterno ao terceiro; o Antigo ao período vivido na claridade das estrelas, o Novo na da lua, e o Evangelho eterno na plena luz do sol; o Antigo à casca da letra, o Novo ao caule e o Evangelho eterno ou do Espírito ao cerne da mesma (VERARDI, 1992, p. 60).

A tudo isso Geraldo de Borgo acrescentava, logo em seguida, em plena sintonia com os textos de Joaquim, que, no terceiro estado do mundo, próprio ao Espírito Santo, diferentemente dos dois estados anteriores, seriam finalmente superadas as mediaçóes hermenêuticas destinadas a decifrar os enigmas e a interpretar as figuras bíblicas e históricas. A compreensão espiritual - e, segundo entendemos aqui, ela é sinônima da própria hermenêutica por concórdia - permitiria o acesso a um modo de conhecimento mais elevado, próprio ao novo estado espiritual em que já não mais seria preciso lançar mão dos procedimentos cabíveis apenas ao interior dos dois períodos anteriores, referentes ao Pai e ao Filho. Significa dizer também que, depois do ingresso no terceiro estado do mundo, o do Espírito, seria superado tudo aquilo que pertencia propriamente ao segundo, como os sacramentos e o clero (a ordo clericorum) e, em última instância, a própria Igreja de Cristo, a qual seria paulatinamente substituída por uma renovada Igreja espiritual (Ecclesia spiritualis) regida pelo Evangelho eterno. 
Uma das diferenças marcantes entre Joaquim e Geraldo é que o jovem franciscano entende o Evangelho eterno como um livro escrito, uma terceira escritura histórica, um Terceiro Testamento redigido com palavras de carne e de terra. E mais, para ele, Joaquim teria sido o seu autor ou ministro, o que implicava de saída a pressuposição de que a terceira escritura corresponderia às próprias obras do abade, como apontam as atas da Comissão de Anagni de 1255 e confirma a maioria dos estudiosos do tema.

O Protocolo de 1255 destaca, logo no início da primeira parte, que Geraldo entendera que os livros do Evangelho eterno seriam constituídos pelas três obras maiores de Joaquim, a saber: a Concórdia entre o Novo e o Antigo Testamento seria o primeiro livro, a Exposição ao Apocalipse, o segundo, e o Saltério de dez cordas, o terceiro. Dessa maneira, o franciscano visivelmente dava um passo importante em relação ao que escrevera o abade de Fiore. Na própria justificativa de sua obra condenada, conforme registra o Protocolo de 1255, Geraldo insinua isso, ao escrever que, "[...] por volta do ano 1200 da Encarnação do Senhor, o espírito de vida dos dois testamentos despertou, a fim de que surgisse o Evangelho eterno." (VERARDI, 1992, p. 60). A seu ver, as obras de Joaquim, escritas por volta de 1200 , teriam revelado o espírito de vida dos dois testamentos. E é com base nelas que Geraldo vai argumentar em defesa da vigência do Evangelho eterno por aqueles dias.

A respeito disso, com razão observam Reeves e Gould (2000, p. 8), quando asseveram que "[...] devemos rebater que ele (Joaquim) náo havia jamais previsto um Terceiro testamento, e menos ainda um testamento composto por seus próprios textos." Com certeza, parece estar fora de disputa o aspecto referente a que Joaquim de Fiore tenha proposto um Terceiro testamento, formado por seus textos; ou, simplesmente, um Terceiro evangelho escrito. É bastante claro, em sua obra, e a historiografia recente é unânime ao admitir isso, que ele jamais sugeriu ou mesmo deu a entender que seus textos poderiam vir a ser tomados como o novo testamento espiritual: o Evangelho eterno a vigorar no terceiro estado.

Diferentemente, numa perspectiva mais radical, o abade repete várias vezes, de acordo com o apóstolo Paulo (2 Cor 3,6), que a perspectiva dos dois testamentos é a de superação de toda e qualquer superfície da letra, pois, para ele, em última instância, a exterioridade da letra é sempre letal, devendo dar lugar ao espírito, que vive e vivifica a compreensão. Não obstante, é preciso ter presente que a proposta de superaçáo da letra não significa, consequentemente, a sua pura e simples exclusão ou rejeição, pois 
que os elementos letais não residem na letra propriamente dita, como pretendera a alegoria alexandrina dos primeiros séculos do cristianismo e alguns estudiosos do joaquimismo, senão na dureza de sua camada exterior. Em última análise, o abade não deixa dúvida: é a "superfície da letra que mata" (superficies litterae que occidit), e não a letra em si (JOAQUIM DE FIORE, 1964c, f. 9b, 14b, 21b, 26b, 61a, 94b, 100a, 126d, 127c, 144b; 1964b, f. $86 a, 107 c, 120 d)$.

Com isso, cremos, de um lado, ter respondido ao primeiro aspecto erigido anteriormente como problema, a saber: se o Evangelho eterno implica uma nova letra, uma nova escritura, um testamento escrito para o terceiro estado. Para Joaquim, o Evangelho eterno não traria uma nova letra, uma nova escritura literal ou mesmo simbólica, por figuras e enigmas. A confusão, endossada pela literatura posterior, a nosso ver, tem origem no texto de Geraldo de Borgo. Depois dele, ganhará vida própria, ao longo da historiografia joaquimita e pseudojoaquimita, as quais citam de segunda e terceira mão aquilo que fora atribuído outrora indevidamente ao abade Joaquim, sem a mínima preocupação em examinar seus textos autênticos.

De outro modo, essa resposta, ainda que parcial, abre outra perspectiva interpretativa. É preciso testar, com base nos autênticos textos joaquimitas, a hipótese de que o Evangelho eterno é um testamento sem letra, em consonância com o que é próprio a cada uma das pessoas da Trindade, a saber: ao Pai, a letra do Antigo Testamento; ao Filho, a do Novo Testamento, que é uma letra de letra, escrita com figuras e enigmas; e ao Espírito, um testamento sem letra, um Evangelho eterno, espiritual, de acordo com as propriedades da terceira pessoa da Trindade.

A hipótese acima nos permite retomar, em outro nível, dois problemas anteriormente deixados de lado. Relembremos. O problema que indagava a respeito da identificação entre o Evangelho eterno e a compreensão espiritual (spiritualis intellectus). E aquele outro que perguntava pela coincidência entre o Evangelho eterno e o Evangelho do reino de Cristo ou Evangelho espiritual de Cristo. É isso que, na sequência, será averiguado, à luz dos textos joaquimitas.

Avaliaremos esses dois problemas com base nos fragmentos dos textos de Joaquim de Fiore, referidos pelo Protocolo de 1255. 


\section{O Evangelho eterno em Joaquim de Fiore}

Três são os momentos principais em que a expressão Evangelho eterno, extraída das obras do abade, vai aparecer no Protocolo de 1255. O primeiro momento refere-se a um de seus últimos trabalhos, o Tractatus super quatuor Evangelia; o segundo, ao seu grande tratado de hermenêutica, a Concordia Novi ac Veteris Testamenti; o terceiro provém do texto dedicado predominantemente ao tema da Trindade, o Psalterium decem chordarum.

Seguiremos essa mesma ordem de apresentação.

1. A primeira vez que a expressão Evangelho eterno aparece é na seção 2 do Protocolo de 1215, que traz por título A nova ordem (VERARDI, 1992, p. 72). Trata-se de uma citação tomada do último texto (incompleto) de Joaquim, o Tractatus super quatuor Evangelia, em que ele, depois de abordar a segunda vinda de Elias, a nova ordem monástica (ordo monachorum) e a Igreja espiritual (Ecclesia spiritualis), identifica o Evangelho do reino ao Evangelho eterno, em um primeiro momento; e, na sequência, distingue os dois, ao acrescentar que Cristo se referiu ao Evangelho do reino e João (supostamente o autor do Apocalipse) ao Evangelho eterno, devido a que os sacramentos, antes transitórios e temporais, passariam a ter o significado de eterno.

Assevera o Tractatus super quatuor Evangelia:

[...] (o espírito) atuará nela [na nova ordem monástica] para que seja pregado o Evangelho do Reino em todo o mundo (Mt 24; Mc 14,9), aquele Evangelho do qual fala João, no Apocalipse (Ap 14,6), onde afirma «Eu vi o anjo de Deus voando no meio do céu e a ele foi dado o Evangelho eterno". Mas que motivo levou o Senhor a dizer Evangelho do Reino, e João Evangelho eterno, senáo que o mandato que recebemos de Cristo e dos Apóstolos, por meio da fé nos sacramentos, que são transitórios e temporais, adquire o significado de eterno? (JOAQUIM DE FIORE, 1930, p. 86, tradução nossa).

A leitura que sugerimos dessa passagem considera que Joaquim, em um primeiro momento, identifica o Evangelho eterno com o Evangelho do reino, tendo em vista que o termo "reino" é um elemento comum, que concerne tanto ao Filho quanto ao Espírito. No entanto, em um segundo momento, Joaquim não está mais se referindo ao que é comum a duas das pessoas da Trindade, senão ao que é próprio a cada uma delas, em sua manifestação no mundo. Daí que ele acentue de modo diverso que Cristo diga "Evangelho do 
reino", ao se referir ao seu mandato, seu reino, seu evangelho, seus sacramentos e seu clero (a ordo clericorum do segundo estado); e João, remetendo-se ao terceiro estado espiritual, diga: "Evangelho eterno", isto é, um Evangelho não mais parcial, nem a cargo de uma Igreja clerical, mas sob a tutela da renovada Igreja espiritual, composta pelos homens espirituais (viri spiritualis) da nova ordem monástica (ordo monachorum) do terceiro estado.

Desse modo, o Evangelho do reino, que no segundo estado tem um significado idêntico ao Evangelho de Cristo, se revestirá, no terceiro, de um novo significado - o significado de eternum -, próprio à figura do Espírito. O reino (regnum), assim, de um significado transitório e parcial, conforme as propriedades atribuídas ao estado filial, passaria, nesse instante (isto é, no interior do terceiro estado), a ter o significado de eterno. Tal interpretação só é possível, se levarmos em conta que, tanto da perspectiva da teoria trinitária quanto da teoria da história, Joaquim tem em vista o entrelaçamento desses dois momentos. São concomitantes as vinte e uma geraçôes do período final (consummatio) do segundo estado, atinente à oclusão do Reino de Cristo, que é transitório; e as vinte e uma geraçóes do período inicial (initiatus ou germinatio) do Reino do Espírito, que já seria compreendido pelo Evangelho eterno. Nesse preciso momento, o Evangelho do Reino, protagonizado pelo Filho, de algum modo estaria se consumando com o final do estado filial, posto que ele é parcial, figurado, enigmático, e de uma graça menor. Assim se deve entender que o Evangelho eterno procede do Evangelho de Cristo, pois, de certo ponto de vista (o da perspectiva da substância comum às três figuras trinitárias), o Evangelho de Cristo tem continuidade com o Espírito, ainda que agora não mais sob a regência de Cristo, mas a do Espírito.

A confusão ocorre, se não distinguirmos suficientemente esses dois momentos, os quais se efetivam de forma concomitante, naquilo que eles indicam o que é comum às duas figuras da Trindade (o Filho e o Espírito) e o que é atribuído propriamente a cada uma delas. $\mathrm{Na}$ terminologia joaquimita, o termo "reino" é um significante comum ao Filho e ao Espírito, mas só com o segundo, com o Espírito, passaria a adquirir o pleno significado de "eterno".

Nesse sentido, é compreensível que a expressão Evangelho do reino, referida ao terceiro estado do mundo, tenha o significado de Evangelho eterno. Também parece plausível que Joaquim, com a expressão "Evangelho do reino", nesse caso, esteja querendo indicar o Reino do Espírito e o seu Evangelho eterno. Bem diferente disso é utilizar como sinônimo de Evangelho eterno, como querem alguns, as expressôes "Reino Espiritual de Cristo" ou "Evange- 
lho Espiritual de Cristo", pois, nesses dois casos, ao incluir Cristo, estaríamos transladando indevidamente para o terceiro estado espiritual as propriedades do segundo, isto é, transferiríamos para o estado espiritual tudo aquilo que é específico à segunda pessoa, seu reinado e seu evangelho, todos transitórios, parciais, e que carregam ainda as marcas da superfície da letra ou estariam cifrados por figuras e enigmas.

2. A segunda ocorrência da expressão Evangelho eterno, seguindo o texto do Protocolo de 1255, provém de uma passagem da Concordia de Joaquim. A passagem está destacada ao final da mesma seção 2 do Protocolo de 1255, em que a Comissão de Anagni, depois de buscar enquadrar Joaquim e, diga-se de passagem, não sem exagerar e forçar os textos -, nas definiçôes de heresia, segundo as formulaçóes de Agostinho, Jerônimo e Isidoro de Sevilha, faz alusão ao Segundo Livro da Concordia (JOAQUIM DE FIORE, 1964b, f. $7 b)$. A passagem é aquela mesma citada por Geraldo de Borgo, em que o abade diz compreender simbolicamente, por terra, o Antigo Testamento; por água, o Novo; e por fogo, "[...] aquele que desceu do céu e devorou tudo" (1Cr 18, 38) - a Comissão acrescenta (pois essa expressão não consta no texto de Joaquim, pelo menos na edição veneziana de 1519) -, “[...] o Evangelho eterno, de acordo com o que já fora dito antes."

Com base nessa passagem da Concordia, a Comissão de Anagni afirma que Joaquim propóe outro testamento para o terceiro estado, um Terceiro testamento, um Evangelho eterno que substituiria as duas letras anteriores. Embora o texto da Concordia não traga a expressão Evangelho eterno, tal como consta no Protocolo de 1255, é bem verdade que esse fragmento se situa no contexto em que o abade explana a respeito da compreensão espiritual da Escritura, facultada pela hermenêutica por concórdia. Nesse sentido, é a compreensão por concórdia que, tal como o fogo, descido do céu, consumirá as palavras compostas por terra e água dos testamentos anteriores. Desse ponto de vista, é a hermenêutica por concórdia que, na realidade, possibilitaria superar os dois testamentos, e poderia ser assim identificada com o Evangelho eterno. Prova disso é que, em complementação, escreve Joaquim de Fiore (1964b, f. 7b), no mesmo locus da Concordia: "[...] esperamos a compreensão espiritual, que suprimirá a terrena superfície da letra, que é de terra e de terra fala" (expectantibus spiritualem intellectum qui terrenam illam superficiem littere, que de terra est et de terra loquitur, evacuando consumat).

Além disso, podemos acrescentar que, apesar de a expressão Evangelho eterno não constar na referida passagem da Concordia, a simbologia do fogo, 
tomada no contexto dos quatro elementos, autoriza a interpretação de que o Evangelho eterno é o modo próprio em que o Espírito in specie igne se manifesta, no terceiro estado, ao proceder dele mesmo, isto é, ao se autoenviar. Diferentes são os outros dois modos. Aquele em que o Espírito procede do Pai, no primeiro estado, in specie aliena como carne ou terra (por exemplo: in specie columba na arca de Noé); e quando procede do Filho, no segundo, também sob outra espécie, identificada pela simbologia da água ou do ar (in susflatione) como, por exemplo, no batismo de Jesus (JOAQUIM DE FIORE, 1964c, f. 6b, 1964a, f. 259c).

Em suma, já podemos indicar que um dos significados possíveis da expressão Evangelho eterno se identifica com o que Joaquim entende por compreensão espiritual (intellectio spiritualis) das escrituras, decorrente da aplicação do método por concórdia. O Evangelho eterno, então, coincide com o próprio significado obtido pela mais alta compreensão espiritual da letra (associada ao fogo), mediante a concórdia entre duas letras (litterae), ou melhor, entre dois significantes (significantia): os significantes literais do Antigo Testamento (terra) e os significantes literais e simbólicos do Novo (água e ar). Portanto, a compreensão espiritual não indicaria uma terceira escritura literal ou histórica, mas a obtenção do mais alto significado da littera, mediante a interpretação (ROSSATTO, 2012). É o que bem expressa a fórmula joaquimita da Concordia (JOAQUIM DE FIORE, 1964b, f. 18b), a qual, emulando o modelo do que é comum na Trindade, sintetiza o procedimento por concórdia, nos seguintes termos: dois significantes resultam em um único significado, dois testamentos, em uma única compreensão espiritual (duo significantia sunt unum significatum; duo testamenta unus spiritualis intellectus).

Ao tratar especificamente o tema da compreensão espiritual (intellectio spiritualis), o Protocolo de 1255, um pouco mais adiante, na seção 5, voltará a comentar a mesma passagem da Concordia (1964b, f. 7b), com base na seguinte anotação de Geraldo: "Neste ponto, Joaquim chama de «terra» o Antigo Testamento, de «água» o Novo Testamento e de «fogo» o Evangelho eterno." (VERARDI, 1992, p. 89). Tal ilação não está incorreta, se entendemos - como já foi concedido antes - que a compreensão espiritual, própria ao terceiro estado do mundo, pode ser identificada com o Evangelho eterno. No entanto, isso não nos autoriza a dizer, como quer Geraldo de Borgo, que as obras do abade, as quais expóem e aplicam a hermenêutica por concórdia, se identificariam com o próprio texto do Evangelho eterno. A rigor, o Evangelho eterno escapa a toda e qualquer corpulência da letra, pois se caracteriza como um ver pleno, um ver 
direto, que não mais possui a opacidade da superfície da letra, nem se perde nos simulacros dos enigmas e das figuras. É precisamente aqui o momento em que o "ver por espelhos e enigmas" (videre per speculum et enigmatem), sugerido pelo apóstolo Paulo (1Cor 13, 9-12), vai dar finalmente lugar ao "ver face a face" ( $v i$ dere facie ad faciem), no qual se retiraria totalmente o véu da letra e se descobriria seu "núcleo oculto" (occulta medulla) (JOAQUIM DE FIORE, 1964c, f. 39a).

3. Ato seguido - e aqui chegamos à terceira ocorrência -, na mesma seção 5, o Protocolo de 1255 agrega uma passagem do Psalterium decem chordarum (JOAQUIM DE FIORE, 1964c, f. 259d-260a). Nessa passagem, também comentada por Geraldo, Joaquim, depois de assegurar que estaria vivendo no início do quinto tempo (de tempore quinto in cuius initius sumus) e que nele se devia esperar a vinda do Espírito, enviado para completar a obra do Filho e operar de modo mais perfeito, adverte que devemos aprender a honrá-lo, do mesmo modo que já foram honrados, cada um a seu tempo, o Pai e o Filho. Na sequência, Joaquim pergunta: e "como devemos honrá-lo?" Ao que responde: "[...] nada é mais adequado para prestar-lhe honras que o seu Evangelho." E volta a perguntar: "qual é o seu Evangelho?” Ao que responde novamente: "Aquele do qual fala João, no Apocalipse: 'eu vi um anjo de Deus que voava no meio do céu e a ele foi dado o Evangelho Eterno' (Ap 14,6). Qual é então o seu Evangelho? Aquele que procede (procedit) do Evangelho de Cristo: 'A letra mata, o espírito vivifica' (2 Cor 3,4)." (VERARDI, 1992, p. 90).

Uma das chaves de leitura dessa passagem é interpretá-la à luz do esquema joaquimita dos cinco tempos, pois é nesse contexto que está inserida tal passagem. A propósito do que compete a cada um dos cinco tempos (tempora), o Psalterium decem chordarum (JOAQUIM DE FIORE, 1964a, f. 259a), complementado pelo Liber introductorius (1964c, f. 5c), apresenta a seguinte caracterização: 1) tempus ante legem, 2) tempus sub legem, 3) tempus sub gratia, 4) tempus sub littera Evangelii ou sub Filius et Spiritus Sanctus e 5) tempus sub spiritualis intellectus ou sub Spiritus Sanctus.

Nessa sequência, é certo que o quinto tempo está previsto para ser vivido no terceiro estado, indicado pelas expressóes "sob a compreensão espiritual" ou, simplesmente, "sob o Espírito Santo". E é em resposta à indagação a respeito do evangelho que vigora no quinto tempo que Joaquim afirma ser o Evangelho eterno; e que esse Evangelho procede do Evangelho de Cristo, isto é, procede do quarto tempo, vivido "sob a letra do Evangelho" (sub littera Evangelii) e sob a dupla influência das figuras trinitárias do Filho e do Espírito Santo. 

Cristo?

Como entender que o Evangelho eterno procede do Evangelho de

Anteriormente, diagnosticamos como problemática a simples identificação entre esses dois evangelhos. Agora, acrescentamos duas justificativas para a defesa de tal posição. Em primeiro lugar, não é possível identificá-los, pois o verbo "proceder" (procedere) indica precisamente que o Evangelho eterno tem origem na compreensão espiritual do Evangelho de Cristo (assim como também do Antigo Testamento); por conseguinte, ele não é o Evangelho de Cristo, mas é o que resulta da interpretação do mesmo. Em segundo, porque podemos entender, de acordo com o esquema geral dos cinco tempos, que se trata de uma alusão ao momento de transição do quarto para o quinto tempo. Segundo a divisão joaquimita da história, é justamente no quarto tempo que temos a segunda processão do Espírito (e daí o uso do verbo procedere), enviado pelo Filho, que se diferencia da primeira processão, na qual, ao final do primeiro estado do mundo, ele fora enviado pelo Pai (JOAQUIM DE FIORE, 1964b, f. 106). O quinto tempo e o período de frutificação do terceiro estado, ambos com início previsto para aqueles dias (isto é, as geraçóes entre 1230 e 1260), passariam a ser vividos na plena liberdade espiritual. O Evangelho eterno indica esse momento de forte e de plena atuação do Espírito na história.

\section{Conclusấo}

A primeira conclusão é a respeito deste último ponto. Com base na avaliação das três passagens citadas dos diferentes textos joaquimitas, podemos concluir que o Evangelho eterno não é uma pura e simples invenção de Geraldo de Borgo, levada a cabo pelos franciscanos espirituais do século XIII, e endossada por radicais, anarquistas e revolucionários, por séculos afora, como querem alguns. Pelo que enfatizamos antes, está fora de cogitação sustentar que o tema não tem amparo na obra de Joaquim de Fiore, ao contrário do que pensam alguns. Mais que isso, entendemos, em suma, que a expressão "Evangelho eterno" carrega consigo três acepçóes principais, que se complementam com amparo na obra do abade de Fiore.

Na sequência, retomamos esses três significados, em forma de conclusão geral.

1. De um ponto de vista estritamente hermenêutico, o Evangelho eterno é a própria compreensão espiritual (intellectio spiritualis) das escrituras, 
mediante a aplicação do método por concórdia, segundo o qual, pela redução dos significantes das duas escrituras, o Antigo e o Novo Testamento, a um só significado, se pode romper a camada externa e dura da superfície da letra e ingressar em seu âmago; e, como resultado disso, o Evangelho eterno é a plena compreensão espiritual das Escrituras. Nesse sentido, a redução dos dois conjuntos de significantes históricos ou literais e simbólicos, constantes nos dois testamentos e na história posterior aos mesmos, nos permite alcançar o significado mais pleno da littera, que é o próprio Evangelho eterno. Tal interpretação não só está de acordo com a teoria hermenêutica do abade, senão que também guarda coerência com sua teoria trinitária e com os diferentes passos de sua teoria da história.

2. Do ponto de vista escatológico ou do fim da história, o Evangelho eterno se identifica com o período áureo de atuação do Espírito, no mundo: é o momento em que o Espírito, que procede do Filho, no quarto tempo, ao final do segundo estado, completa sua tarefa no Reino de Cristo. Mas também é o momento em que o mesmo Espírito, proveniente de si próprio, atuará soberanamente e com todos os seus atributos, no decorrer do quinto tempo, a ser vivido no terceiro estado espiritual.

Devido a isso, aqui ganham destaques dois significados distintos, ainda que complementares, do Evangelho eterno: a) em um sentido, o Evangelho eterno pode ser tomado como sinônimo de Evangelho do Reino, pois a expressão Evangelho do Reino diz respeito tanto ao cumprimento do Evangelho de Cristo, quanto à realização efetiva do período que se inicia com o Reino do Espírito; e b) em outro, o Evangelho eterno não poderá ser identificado apenas com o Evangelho do Reino de Cristo, pois o Reino do Espírito não só procede, em um primeiro momento, mas sucede o Reino de Cristo, em um segundo. É, aliás, o Espírito que eleva o Reino de Cristo, de parcial e incompleto, à condição de eterno, dando início a uma nova economia espiritual posterior a Cristo, ao seu Evangelho, sua Igreja e todas as figuras pertinentes ao segundo estado.

Em última instância, tem de ficar claro que o tempo e o estado de Cristo seriam superados, no decorrer da história, por um tempo (o quinto) e um estado (o terceiro) de maior plenitude, tendo como consequência a gradativa secundarização de tudo aquilo que diz respeito propriamente a Cristo e ao cristianismo. É precisamente contra essa consequência decorrente da hermenêutica joaquimita que, já no século XIII, Tomás de Aquino, no calor das polêmicas em torno do franciscanismo espiritual, retoma a tradicional in- 
terpretação agostiniana de que o tempo de Cristo já é a plenitude dos tempos (tempus plenitudines), e não o tempo do Espírito, como queria Joaquim de Fiore e seus seguidores. A propósito, Tomás de Aquino (1980, p. 2035) escreve, na Suma teológica (II ${ }^{\mathrm{a}}$-IIa, q. 1, a. 7, ad 4): "A consumação última da graça foi feita por Cristo; por isso, o seu tempo se chama tempo da plenitude" (Ultima consummatio gratiae facta est per Christum: unde et tempus eius dicitur tempus plenitudinis, ad Gal. IV, 4).

3. Sob o ponto de vista eclesiológico, o Evangelho eterno é o Evangelho do Espírito e, por isso mesmo, não poderia indicar apenas um cristianismo espiritual renovado, nem um Evangelho espiritual de Cristo, ou simplesmente o Reino espiritual de Cristo. Também não poderia indicar tão somente a superação da "cristandade" (cristianità), como quer Gianni Vattimo; ou, ainda, a reconstituiçáo do sentido do cristianismo, como se derivaria da hermenêutica de Paul Ricoeur (ainda que ele não esteja aplicando a Joaquim de Fiore, autor que talvez nem conheça). Se fosse apenas isso, a superação apontada por Joaquim nada mais seria que a troca de uma igreja por outra: a igreja cristã inautêntica do segundo estado (ou da cristandade, para Vattimo) daria lugar a outra igreja cristã mais autêntica do terceiro (a do cristianismo). Os que interpretam desse modo a hermenêutica joaquimita tomam o aspecto secundário pelo principal. O Evangelho de Cristo e a sua Igreja não podem, em momento algum, recobrir a totalidade do significado do Evangelho do Espírito ou eterno, e da futura Igreja espiritual do terceiro estado, a qual seria protagonizada por homens espirituais (viri spiritualis) da nova ordem monástica (ordo monachorum), tais como São Bento de Núrsia.

Por todos esses motivos - e principalmente por implicar a tácita indicação da superação do cristianismo, correspondente ao estado filial e à Igreja clerical -, a hermenêutica que propóe o Evangelho do Espírito ou eterno ainda continua sendo uma hermenêutica condenada. A diferença é que a condenação medieval era mais declarada, enquanto a atual é menos visível, subterrânea, sub-reptícia.

ROSSATTO, N. D. The eternal Gospel: hermeneutics and the end of history in Joachim of Fiore. Trans/form/açäo, Marília, v. 41, n. 1, p. 61-80, Jan./Mar., 2018. 
ABstract: This study evaluates the theme of the eternal gospel in Joachim of Fiore. The central hypothesis is that Joachim of Fiore understands the eternal gospel as a new message derived from the spiritual comprehension of the scriptures, valid within the third state of the world - the so-called spiritual state. The defense of this hypothesis implies the rejection of the notion of the existence a new scripture for the third state of the world, an idea advocated by the Franciscan Gerard of Borgo, condemned in 1255. Unlike most students of the theme, however, at other points in his work Fiore implies that there could be a new gospel, the eternal gospel, which would replace the Gospel of Christ and his Kingdom and be destined reign over the third spiritual state.

KeYwords: Joachim of Fiore, Franciscans, Eternal gospel, Hermeneutics, End of history.

\section{REFERÊNCIAS}

AEGERTER, E. L'Evangile eternel. Fragments. Paris: Rieder, 1928.

CROCCO, A. L'Età dello Spirito Santo in Gioacchino da Fiore. Humanitas, v. 8, p. 728742, 1954.

DE LUBAC, H. La postérité spirituelle de Joachim de Flora. Tomo I: de Joachim à Schelling. Paris: Lethielleux, 1979.

ELIADE, M. El mito del eterno retorno: arquetipos y repetición. Barcelona: Península, 1996.

JOAQUIM DE FIORE. Tractatus super quatuor Evangelia. Roma: Istituto Storico Italiano, 1930. 1964a. . Psalterium decem chordarum. Venedig 1527, reprint Frankfurt: Minerva,

$1964 b$.

Concordia Novi ac Veteris Testamenti. Venedig, 1519, reprint Frankfurt: Minerva,

. Expositio in Apocalypsim (com Liber introductorius in Apocalipsis). Venedig: 1527, reprint Frankfurt: Minerva, 1964c.

. Trattati sui quattro Vangeli. Tradução italiana de L. Pellegrini, revisão de G. L. Potestà. Roma: Viella, 1999.

. Introdução ao Apocalipse (Prephacio super Apocalipsis). Tradução ao português

de N. D. Rossatto. Veritas, Porto Alegre, RS, v. 47, n. 3, p. 453-471, set. 2002.

LEFEBVRE, H. Hegel, Marx, Nietzsche: o el reino de las sombras. Madrid: Siglo XXI, 1976.

MOTTU, H. La manifestazione dello Spirito secondo Gioacchino da Fiore. Traduçáo de Roberto Usseglio. Roma: Marietti, 1983.

REEVES, M.; GOULD, W. Gioacchino da Fiore e il mito dell'Evangelo eterno nella cultura europea. Roma: Viella, 2000.

RICOEUR, P. O conflito das interpretações: ensaios de hermenêutica. Tradução de Hilton Japiassu. Rio de Janeiro: Imago, 1976. 
ROSSATTO, N. D. Joaquim de Fiore: Trindade e nova era. Porto Alegre: EDIPUCRS, 2004. . Hermenêutica medieval: a compreensão espiritual de Joaquim de Fiore. Trans/ Form/Ação, Marília, SP, v. 35, Edição Especial, p. 99-118, 2012. ; MARASCHIN, L. T.; NASCIMENTO, C. R. Evangelho eterno: a hermenêutica condenada. Com tradução ao português do Protocolo de 1255. Filosofia Unisinos, São Leopoldo, v. 11, n. 3, p. 398-339, set/dez 2010.

TOMÁS DE AQUINO. Suma teológica. 2a Parte da 2a Parte, v. V, 2. ed. Tradução de Alexandre Corrêa. Porto Alegre: EST/Sulina; Caxias do Sul: UCS, 1980.

VATTIMO, G. Depois da cristandade: por um cristianismo não religioso. Tradução de Cynthia Marques. Rio de Janeiro: Record, 2004.

VERARDI, L. Gioacchino da Fiore: il protocollo di Anagni. Tradução italiana e reedição do texto latino de H. Denifle: Protocol der Commission zu Anagni. Anno 1255. Cosenza: Orizzonti Meridionali, 1992. 